\title{
Emission control of InGaN nanocolumns grown by molecular-beam epitaxy on $\mathrm{Si}(111)$ substrates
}

\author{
S. Albert, ${ }^{1, a)}$ A. Bengoechea-Encabo, ${ }^{1}$ P. Lefebvre, ${ }^{1,2}$ M. A. Sanchez-Garcia, ${ }^{1}$ E. Calleja, ${ }^{1}$ \\ U. Jahn, ${ }^{3}$ and A. Trampert ${ }^{3}$ \\ ${ }^{1}$ ISOM and Departamento de Ingeniería Electrónica, ETSI Telecomunicación, Universidad Politécnica \\ de Madrid, Ciudad Universitaria s/n, 28040 Madrid, Spain \\ ${ }^{2}$ Université Montpellier 2, F-34095 Montpellier, Cedex 5 , France \\ ${ }^{3}$ Paul-Drude-Institut für Festköperelektronik, Hausvogteiplatz 5-7, 10117 Berlin, Germany
}

\begin{abstract}
This work studies the effect of the growth temperature on the morphology and emission characteristics of self-assembled InGaN nanocolumns grown by plasma assisted molecular beam epitaxy. Morphology changes are assessed by scanning electron microscopy, while emission is measured by photoluminescence. Within the growth temperature range of 750 to $650^{\circ} \mathrm{C}$, an increase in In incorporation for decreasing temperature is observed. This effect allows tailoring the InGaN nanocolumns emission line shape by using temperature gradients during growth. Depending on the gradient rate, span, and sign, broad emission line shapes are obtained, covering the yellow to green range, even yielding white emission. (C) 2011 American Institute of Physics. [doi:10.1063/1.3644986]
\end{abstract}

Group III-nitride semiconductors are very appealing for applications in optoelectronic devices, in particular, InGaN alloys for light emitters working in the whole visible spectral region. ${ }^{1-3}$ So far studies focused mainly on InGaN quantum well (QW) structures, though their performance is limited by: (1) the quantum confined stark effect (QCSE) and (2) the high defect density. On the other hand, one-dimensional structures such as nanocolumns (NCs) grow dislocation- and strain-free on different substrates. ${ }^{4-8}$ InGaN quantum disk (QDisk) structures placed within NCs yield a strong light emission enhancement as compared to QWs due to reduced strain and internal electric fields. ${ }^{9-13}$ In this work, selfassembled InGaN NCs have been fabricated by plasmaassisted molecular-beam epitaxy (PAMBE) at different sample temperatures to study the In incorporation. Next, the optical emission line-shape from the InGaN NCs has been tailored by means of a temperature gradient aiming to achieve broad emission (white).

All samples were grown on $\mathrm{Si}(111)$. The molecular fluxes $\left(\Phi_{\mathrm{Ga}}, \Phi_{\mathrm{In}}, \Phi_{\mathrm{N}}\right)$ were calibrated in $(0001) \mathrm{GaN}$ and (0001) InN growth rate units $(\mathrm{nm} / \mathrm{min}) .{ }^{14}$ In order to study the effect of the growth temperature, a first series (A) of InGaN NCs were grown following a two-step method: (1) $1 \mathrm{~h}$ growth of $\mathrm{GaN} \mathrm{NCs}$ at $800^{\circ} \mathrm{C}$, with $\Phi_{\mathrm{Ga}}=4.3 \mathrm{~nm} / \mathrm{min}$ and $\Phi_{\mathrm{N}}=14 \mathrm{~nm} / \mathrm{min}$, and (2) $1 \mathrm{~h}$ growth of InGaN NCs on top of the GaN NCs, at different fixed temperatures $\left(650^{\circ} \mathrm{C}\right.$, $675^{\circ} \mathrm{C}, 700^{\circ} \mathrm{C}, 725^{\circ} \mathrm{C}$, and $750^{\circ} \mathrm{C}$ ), keeping the same previous $\Phi_{\mathrm{Ga}}, \Phi_{\mathrm{N}}$ values and $\Phi_{\mathrm{In}}=\Phi_{\mathrm{Ga}}$. A second series (B) of samples were grown under the same conditions for the $\mathrm{GaN}$ part as in series A, but using a temperature gradient during the InGaN growth. A reference GaN NCs sample was grown for $2 \mathrm{~h}$ (same conditions as for the GaN part in series $\mathrm{A}$ and B) in order to estimate any effect of the InGaN growth on the NC morphology.

\footnotetext{
${ }^{a)}$ Author to whom correspondence should be addressed. Electronic mail: salbert@ isom.upm.es.
}

Figure 1 shows the cross-sectional scanning electron microscope (SEM) pictures of the reference GaN sample (Figure 1(a)) and two InGaN/GaN NCs samples (Figures 1(b) and 1(c)) with the InGaN NC part grown at $700^{\circ} \mathrm{C}$ and $650^{\circ} \mathrm{C}$, respectively (series A). Without considering the nucleation time, the GaN NCs reference sample (Figure 1(a)) shows a growth rate of about $10 \mathrm{~nm} / \mathrm{min}$. It has been shown previously that the growth rate of $\mathrm{GaN}$ NCs is limited by the Ga-flux. ${ }^{15}$ For a Ga-flux of $4.3 \mathrm{~nm} / \mathrm{min}$ and considering the strong $\mathrm{GaN}$ decomposition and $\mathrm{Ga}$ desorption rates at $800^{\circ} \mathrm{C},{ }^{14,16}$ we assume that the diffusion of $\mathrm{Ga}$-ad-atoms upon the NCs sidewalls is the main $\mathrm{Ga}$ source for the $\mathrm{GaN}$ NCs growth. ${ }^{17}$ For InGaN NCs grown at $700^{\circ} \mathrm{C}$ (Figure 1(b)) (notice that the first $\mathrm{GaN}$ part is always grown at $800^{\circ} \mathrm{C}$ ). a decrease in total $\mathrm{NC}$ height (around 1.0 versus $1.2 \mu \mathrm{m})$ and an increase in diameter at the top region of the

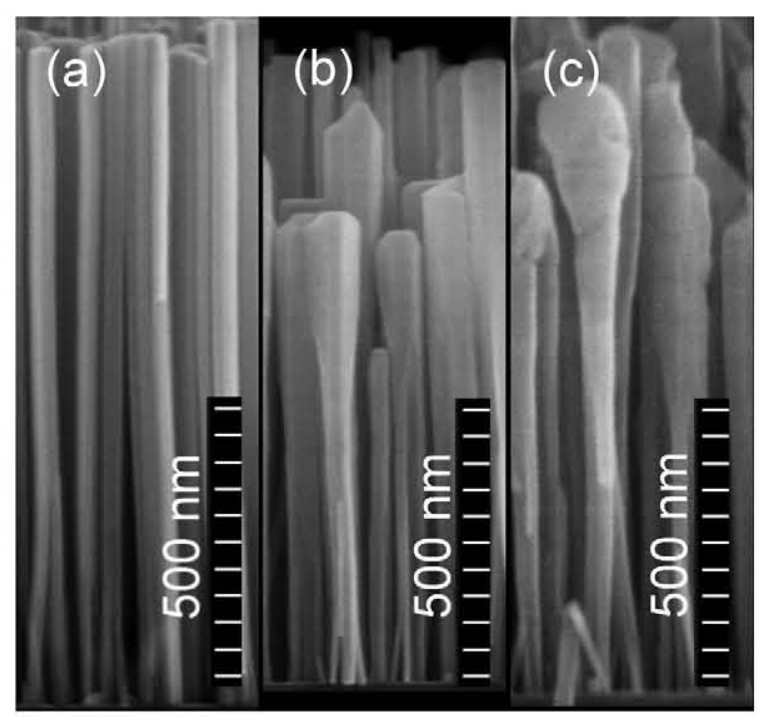

FIG. 1. SEM pictures of (a) GaN NCs reference sample (grown at $800^{\circ} \mathrm{C}$ ); (b) and (c) are selected $\mathrm{InGaN} / \mathrm{GaN}$ NCs samples of series $\mathrm{A}$ with $\mathrm{InGaN}$ grown at $700^{\circ} \mathrm{C}$ and $650^{\circ} \mathrm{C}$, respectively. 
NC (around $100 \mathrm{~nm}$ versus $50 \mathrm{~nm}$ ) can be observed, as compared with the reference GaN sample (Figure 1(a)). Since the total height of the reference sample is $1.2 \mu \mathrm{m}$ for $2 \mathrm{~h}$ growth, the height of the InGaN part in the InGaN/GaN NCs (1 $+1 \mathrm{~h}$ ) can be directly estimated and the $\mathrm{InGaN}$ growth rate is also determined for each growth temperature. These values are plotted in Figure 2 indicating an initial decrease in the InGaN growth rate when lowering the growth temperature from 750 to $700^{\circ} \mathrm{C}$ and a partial recovery for temperatures below $700^{\circ} \mathrm{C}$. The total metal flux used for the InGaN NC part: $\Phi_{\mathrm{Ga}}+\Phi_{\mathrm{In}}$ (being $\Phi_{\mathrm{Ga}}$ the same used in the reference GaN sample) should be close to $\Phi_{\mathrm{Ga}}$ in the temperature range from 750 to $700^{\circ} \mathrm{C}$ because of the very strong In desorption. ${ }^{18}$ Thus, the reduction of the Ga-adatoms diffusion length from 750 to $700^{\circ} \mathrm{C}$ (less atoms reach the NCs top) may account for the observed reduction of the growth rate. For temperatures below $700^{\circ} \mathrm{C}$, a reduced In desorption may account for the partial recovery of the growth rate, as shown in Figure 2. The NC diameter is observed to start increasing below the nominal $\mathrm{GaN} / \mathrm{InGaN} \mathrm{NC}$ interface, gradually widening up to the top (Figure 1(b)). Cathodoluminescence data (not shown) reveals that emissions related to InGaN arise only from the material located above this interface, which points to $\mathrm{Ga}$ ad-atoms being responsible for the diameter change below it. Indeed, a lower growth temperature would increase the residence time of climbing $\mathrm{Ga}$ ad-atoms along the NC sidewalls, thus, enhancing their probability to incorporate on the sides before desorbing or getting to the NC top. ${ }^{17}$ Notice that above the GaN/InGaN NC interface both In and $\mathrm{Ga}$ will contribute to the lateral growth. This diameter increase may also add to reduce the vertical growth rate and, thus, the overall $\mathrm{NC}$ height. At $650^{\circ} \mathrm{C}$ (Fig. 1(c)) and below it, the diameter increase may lead to NCs coalescence.

Photoluminescence (PL) spectra taken at low temperature reveal very sharp peaks in the ultraviolet (UV) region (not shown) related to the GaN NCs part, which is a proof of its high material quality. From PL data, Figure 2 shows the In incorporation dependence on the growth temperature. At $750^{\circ} \mathrm{C}$, the InGaN emission is barely seen, pointing to an almost negligible In incorporation. ${ }^{18}$ For lower temperatures, the In content can be estimated from the InGaN PL peak energy position according to $\mathrm{Wu}$ et al., ${ }^{19}$ being $\sim 15 \%$ at

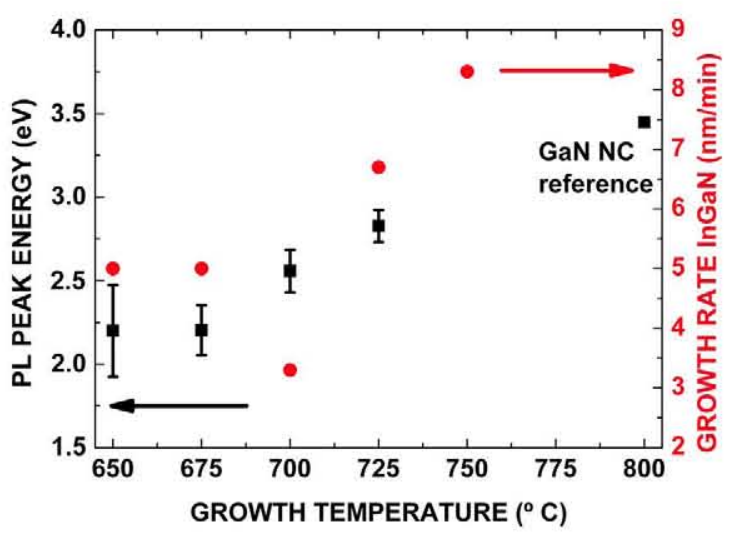

FIG. 2. (Color online) Low temperature PL peaks and FWHM of InGaN/ GaN NCs grown at different temperatures (squares). Circles show growth rate dependence on temperature of the $\mathrm{InGaN} \mathrm{NCs} \mathrm{part.}$ $725^{\circ} \mathrm{C}, \sim 22 \%$ at $700^{\circ} \mathrm{C}$, and $33 \%$ at $650^{\circ} \mathrm{C}$. Vertical bars in Figure 2 refer to the PL peak full width at half maximum (FWHM) values. The broadening of the PL line width for higher In-contents is expected from increasing alloy disorder and does not necessarily imply crystal quality degradation.

In the first two samples of series $\mathrm{B}$, the InGaN part was grown using temperature gradients from $650{ }^{\circ} \mathrm{C}$ to $750^{\circ} \mathrm{C}$ at a constant rate of $\pm 2^{\circ} \mathrm{C} / \mathrm{min}$ ( \pm stands for increasing or decreasing temperatures). As a result, a graded In composition and broad PL emission are expected. Figure 3 shows normalized low temperature PL spectra of these two graded InGaN NCs. The change in the direction of the temperature gradient (positive or negative) does not significantly modify the emission broadening (FWHM of $0.5 \mathrm{eV}$ and $0.55 \mathrm{eV}$ ), but it strongly affects the spectral range covered, since the peak emission shifts from $2.59 \mathrm{eV}$ to $2.16 \mathrm{eV}$. This difference can be explained by thermal decomposition of $\mathrm{InGaN}$ during growth. When applying a positive gradient (from $650{ }^{\circ} \mathrm{C}$ to $750^{\circ} \mathrm{C}$ ), the high In-content part (lower T) which is grown first will tend to decompose as the temperature rises. Then, most of the PL emission arises from the average- and lowIn-content parts (blue-like). However, when applying a negative gradient (from $750^{\circ} \mathrm{C}$ to $650^{\circ} \mathrm{C}$ ), the high In-content part is grown at the end, so that the thermal decomposition of this region is much less severe. As a consequence, the low energy emission (green-like) is enhanced. The relative low intensity of the blue emission in this case may be due to carrier diffusion towards the high-In content region that has a lower bandgap. In both cases, white light is generated at low temperature. At room temperature (RT), the overall PL intensity significantly drops and the blue part in both spectra quenches much faster than the green one. This last effect is most probably related again to enhanced carrier diffusion by thermal escape from low In-content regions to high Incontent ones. Both samples emit in the green region at RT. In order to further enhance the blue emission, a third sample was grown using a two-step temperature gradient, namely, a first step from $750^{\circ} \mathrm{C}$ to $700^{\circ} \mathrm{C}$ at a rate of $-1.3^{\circ} \mathrm{C} / \mathrm{min}$ and a second step from $700^{\circ} \mathrm{C}$ to $650{ }^{\circ} \mathrm{C}$ at a rate of $-4.1{ }^{\circ} \mathrm{C} /$ $\min$. The aim was to shorten the time the sample was subjected to low temperature, thus reducing the high In-content

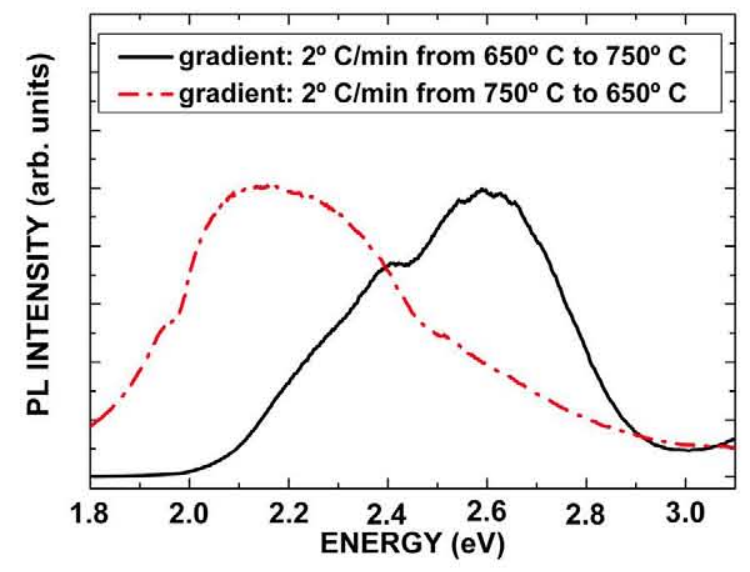

FIG. 3. (Color online) Normalized low temperature (11 K) PL spectra of InGaN/GaN NCs grown with a temperature gradient at a constant rate of $2{ }^{\circ} \mathrm{C} /$ min from $650^{\circ} \mathrm{C}$ to $750^{\circ} \mathrm{C}$ (solid line) and from $750^{\circ} \mathrm{C}$ to $650^{\circ} \mathrm{C}$ (dashed line). 


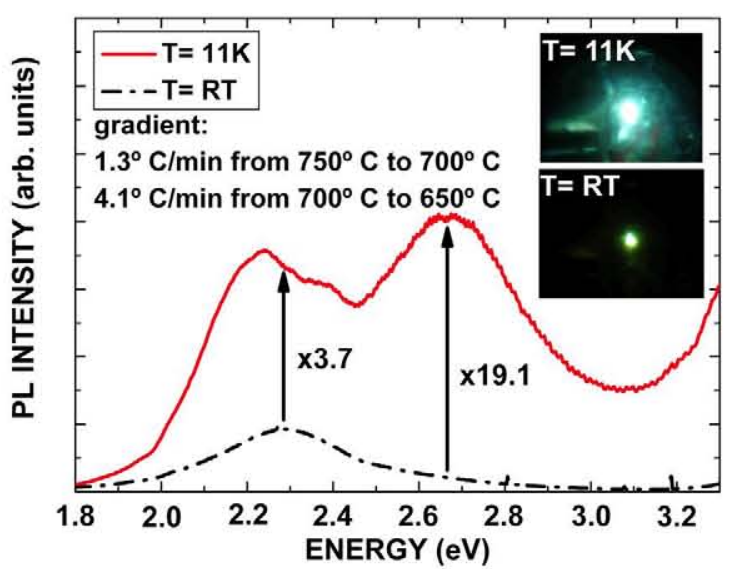

FIG. 4. (Color online) Low and room temperature PL spectra of InGaN/ GaN NCs grown with a two-step temperature gradient. White emission at low temperature and green-whitish emission at RT were observed (inset).

part and enhancing the low In-content part. Figure 4 shows the PL spectra (low and RT) of this sample, where a significant enhancement of the blue emission is observed at $11 \mathrm{~K}$. A significant quenching of the blue emission is observed at RT, though lower than that measured in samples with one step gradient. The reason most likely is the one already mentioned, since the same physical mechanisms must be present in all samples. Emission at RT is green-whitish.

In summary, self-assembled InGaN/GaN NCs were successfully grown by PAMBE on $\mathrm{Si}(111)$. The effects of the growth temperature on the NCs morphology have been described in terms of metal atoms diffusivity along the NCs sidewalls, in agreement with the model reported in Ref. 17. Indium incorporation strongly depends on the growth temperature reaching up to $33 \%$ at $650^{\circ} \mathrm{C}$. Temperature gradients (single and two-step) provide a simple tool to tailor the emission line shape broadening. White emission at low temperature and green-whitish emission at RT were achieved.
We acknowledge partial financial support by the EU FP7 via Contract No. SMASH 228999-2 and the Initial training network RAINBOW Project No. PITN-GA-2008-213238 and by Spanish Project Nos. CAM/P2009/ESP-1503 and MICINN MAT2008-04815.

${ }^{1}$ S. Nakamura, G. Fasol, and S. J. Pearton, The Blue Laser Diode: The Complete Story (Springer, Berlin, 2000).

${ }^{2}$ F. K. Yam and Z. Hassan, Superlattices Microstruct. 43, 1 (2008).

${ }^{3}$ T. Kuykendall, P. Ulrich, S. Aloni, and P. Yang, Nature Mater. 6, 952 (2007).

${ }^{4}$ E. Calleja, M. A. Sanchez-Garcia, F. J. Sanchez, F. Calle, F. B. Naranjo, E. Munoz, U. Jahn, and K. Ploog, Phys. Rev. B 62, 16826 (2000).

${ }^{5}$ R. Meijers, T. Richter, R. Calarco, T. Stoica, H. P. Bochem, M. Marso, and H. Lüth, J. Cryst. Growth 289, 381 (2006).

${ }^{6}$ N. Thillosen, K. Sebald, H. Hardtdegen, R. Meijers, R. Calarco, S. Montanari, N. Kaluza, J. Gutowski, and H. Lüth, Nano Lett. 6, 704 (2006).

${ }^{7}$ M. Yoshizawa, A. Kikuchi, M. Mori, N. Fujita, and K. Kishino, Jpn. J. Appl. Phys. 36, L459 (1997).

${ }^{8}$ Y. S. Park, C. M. Park, D. J. Fu, T. W. Kang, and J. E. Oh, Appl. Phys. Lett. 85, 5718 (2004).

${ }^{9}$ H.-M. Kim, Y.-H. Cho, H. Lee, S. I. Kim, S. R. Ryu, D. Y. Kim, T. W. Kang, and K. S. Chung, Nano Lett. 4, 1059 (2004).

${ }^{10}$ C. H. Chiu, T. C. Lu, H. W. Huang, C. F. Lai, C. C. Kao, J. T. Chu, C. C. Yu, H. C. Kuo, S. C. Wang, C. F. Lin, and T. H. Hsueh, Nanotechnology 18, 445201 (2007).

${ }^{11}$ Y. Kawakami, S. Suzuki, A. Kaneta, M. Funato, A. Kikuchi, and K. Kishino, Appl. Phys. Lett. 89, 163124 (2006).

${ }^{12}$ H.-Y. Chen, H.-W. Lin, C.-H. Shen, and S. Gwo, Appl. Phys. Lett. 89, 243105 (2006).

${ }^{13}$ H.-S. Chen, D.-M. Yeh, Y.-C. Lu, C.-Y. Chen, C.-F. Huang, T.-Y. Tang, C. C. Yang, C.-S. Wu, and C.-D. Chen, Nanotechnology 17, 1454 (2006).

${ }^{14}$ B. Heying, R. Averbeck, L. F. Chen, E. Haus, H. Riechert, and J. S. Speck, J. Appl. Phys. 88, 1855 (2000).

${ }^{15}$ S. Fernández-Garrido, J. Grandal, E. Calleja, M. A. Sánchez-Garcia, and D. López-Romero, J. Appl. Phys. 106, 126102 (2009).

${ }^{16}$ S. Fernández-Garrido, G. Koblmüller, E. Calleja, and J. S. Speck, J. Appl. Phys. 104, 033541 (2008).

${ }^{17}$ J. Ristíc, E. Calleja, S. Fernández-Garrido, L. Cerutti, A. Trampert, U. Jahn, and K. H. Ploog, J. Cryst. Growth 310, 4035 (2008).

${ }^{18}$ C. S. Gallinat, G. Koblmüller, J. S. Brown, and J. S. Speck, J. Appl. Phys. 102, 064907 (2007).

${ }^{19} \mathrm{~J}$. Wu and W. Walukiewicz, Superlattices Microstruct. 34, 63 (2003). 